\title{
The Weight Assessment and its Relation to Hemophilia Joint Health Score in Hemophilic Patients
}

\author{
Osama Roshdi El-Safy, Ahmed Mohammed Abdel Moneim, Nora Mohammed Ali Mohammed \\ Department of Pediatrics, Faculty of Medicine - Zagazig University, Egypt
}

*Corresponding Author: Nora Mohammed Ali Mohammed, Mobile: (+20) 1002548434, E-mail: haidym249ali@gmail.com

\begin{abstract}
Background: Haemophilia is a group of hereditary disorders that impair the body's ability to control blood clotting or coagulation. Joint bleeding (hemarthrosis) results in synovial hypertrophy and damage of the cartilage, leading to joint destruction with recurrent bleeding episodes (hemophilic arthropathy).

Objective: To assess weight of hemophilic children and correlate the weight to Hemophilia Joint Health Score.

Methods: The sample size included was 66 patients with hemophilia in Zagazig city between October 2019 and March 2020. They were categorized according to presence of arthropathy or not [Two groups; one group with hemophilic arthropathy and the other group without hemophilic arthropathy]. All patients were subjected to full history taking including personal history, thorough clinical examination [assessment of vital signs and color, assessment of any bone deformity, pain or muscle weakness and Hemophilia Joint Health Score ] and weight assessment,

Results: Our case control study showing male predominance in both groups. In hemophilic arthropathy, 100\% (10.68 $\pm 4.28)$ and without hemophilic arthropathy $97 \%(7.17 \pm 4.12)$ and more prevalence of hemophilia A [factor V111 deficiency] in both groups (with H.A.97\% \& without H.A.78.8\%). In addition, our study reported that most common site of bleeding in hemophilic patients rather than big joints affection; gum [18.2\%] then gum \& teeth [12.1\%]. Increased weight was found more in hemophilia with arthropathy than in hemophilia without arthropathy.

Conclusion: Our case control study showing male predominance and more prevalence of hemophilia A than B in both hemophilic groups (with or without hemoarthropathy). Weight was significantly increased in hemophilia with arthropathy group than in hemophilia without arthropathy group.
\end{abstract}

Keywords: Weight assessment, Hemophilia Joint Health Score, Hemophilic patients.

\section{INTRODUCTION}

Hemophilic arthropathy is a disabling condition characterized by joint impairment, chronic pain, and reduced quality of life. Recent evidence indicates that intra-articular inflammation and angiogenesis may be pivotal processes in the pathogenic cascade of hemophilic arthropathy. Joint bleeding favors iron release from hemoglobin, thus inducing a chronic inflammatory process mediated by cytokines and proangiogenic factors and consequently leading to progressive synovial pannus growth and articular cartilage damage (1). The pathophysiology of hemophilic arthropathy shares some clinical and biological features with rheumatoid arthritis (RA) and osteoarthritis (OA), especially RA-related synovitis and bone resorption and OA-related articular cartilage degeneration (2).

Patients are treated with intravenous replacement of coagulation F VIII and F IX as standard of care. Replacement factor is dosed according to body weight and aims to arrest or prevent excessive bleeding when administered on-demand or as prophylaxis. Historically, patients were not treated routinely with replacement factor amid fear of viral contamination or due to lack of access to treatment in developing nations, leading to an older haemophilia population with damaged joints, decreased mobility and chronic synovitis ${ }^{(3)}$. Access to virus-free coagulation factor has increased. Younger patients with hemophilia $(\mathrm{PWH})$ in developed countries are often treated with routine intensive prophylaxis regimens and benefit from a reduced physical impact of haemophilia and preservation of musculoskeletal function. However, the availability of replacement factor for prophylactic treatment still varies between regions, with continued restricted access in developing nations and poor long-term outcomes observed with episodic treatment ${ }^{(4)}$.

Emerging therapies, such as non-factor replacement therapy and gene therapy, have the potential to correct haemostasis and improve treatment outcomes for PWH. Advances in treatment may allow greater scope to address comorbidities that impact haemophilia management, including overweight and obesity ${ }^{(5)}$.

'Overweight' and 'obesity' are often classified according to the following body mass index (BMI) categories: healthy weight (BMI 18.5-24.9 kg/m²), overweight (BMI $25-29.9 \mathrm{~kg} / \mathrm{m}^{2}$ ), obese (BMI $\geq 30$ $\mathrm{kg} / \mathrm{m}^{2}$ ) or severely obese (BMI $\left.\geq 40 \mathrm{~kg} / \mathrm{m}^{2}\right)^{(6)}$.

The World Health Organization ${ }^{(6)}$ estimated that obesity prevalence in the general population has tripled since 1975 and affects approximately $13 \%$ of adults globally; a further $39 \%$ of adults are classified as overweigh. The obesity epidemic carries significant health implications for the general population, including increased risk of high blood pressure, type 2 
diabetes, stroke, coronary heart disease, osteoarthritis, sleep apnea, kidney disease, liver disease, clinical depression and certain types of cancer.

The study aimed to assess weight of hemophilic children and correlate the weight to Hemophilia Joint Health Score.

\section{PATIENTS AND METHODS}

Case control study had been conducted at Pediatric Department of Faculty of Medicine in Zagazig University between October 2019 and March 2020.

\section{Ethical approval:}

The study was approved by the Ethics Board of Zagazig University and an informed written consent was taken from each participant in the study.

Sample size: Using epi-info, power $80 \%$ and CI 95\%, assuming that mean \pm SD of feelings in health-related quality of life in group I was $16.64 \pm 20.4$ and $30.9 \pm$ 20.3 in group II. Therefore, the total sample had been 66 children patients already diagnosed as hemophilia. These patients were classified into two groups: Group I: 33 hemophilic patients with arthropathy and Group II: 33 hemophilic patients without arthropathy. Level of clotting factor VIII or IX less than $10 \%$ in both groups.

Inclusion Criteria: Patients diagnosed hemophilia A or $\mathrm{B}$, age up to 18 years and both sex had been included.

Exclusion Criteria: Patients older than 18 years, patients with congenital anomalies, patients with other bleeding disorders as defect in factors V, VII, I, II, or combined deficiency of factor V and VIII (F5 \& F8), patients with hemophilic arthropathy combined with other hematological diseases and patient with other bone and joint diseases.

Both sex had been included in the study and were subjected to the following:

1) Full history taking including personal history.

2) Thorough clinical examination: Assessment of vital signs and color, assessment of any bone deformity, pain or muscle weakness and hemophilia Joint Health Score (HJHS).

3) Assessment of anthropometric measurements on WHO growth chart (Weight/age, height/age and BMI/age).

4) Drugs in hemophilic patients.
5) Nutritional assessment: by assessment of Weight/age, height/age and BMI/age, M.A.C., Mid-thigh circumference and Waist circumference.

\section{Statistical Analysis}

The data were coded, entered and processed on computer using SPSS (version 18). The results were represented in tabular forms then interpreted. Mean, standard deviation, range, frequency, and percentage were used as descriptive statistics. Chi-Square test $\mathbf{X}^{\mathbf{2}}$ was used to test the association variables for categorical data. Student's t-test was used to assess the statistical significance of the difference between two population means in a study involving independent samples. Student's paired t-test was used to assess the statistical significance of the difference between two population means in a study involving paired samples. ANOVA (F test) for normal quantitative variables, to compare between more than two groups, and Post Hoc test (LSD) for pairwise comparisons. P-value $\leq 0.05$ was considered significant.

\section{RESULTS}

There was no statistically significant difference between hemophilia with arthropathy group and hemophilia without arthropathy group regarding sex. There were statistically significant increase in age (years) among hemophilia with arthropathy group than hemophilia without arthropathy group (Table 1).

There was no statistically significant difference between hemophilia with arthropathy group and hemophilia without arthropathy group regarding type of factor deficiency (Table 2).

There was statistically significant difference between hemophilia with arthropathy group and hemophilia without arthropathy group regarding degree of severity (factor level). There was significant increase in risk of arthropathy in severe hemophilia (Table 3).

There was statistically significant difference between hemophilia with arthropathy group and hemophilia without arthropathy group regarding site of bleeding if found (Table 4).

Table (5) showed that there was significant increase in number of hemophilic patients with normal weigh $\left(25^{\text {th }}-75^{\text {th }}\right)$ in those without joint involvement than in arthropathy group regarding weight. In addition, this table showed that there was significant increase in number of hemophilic patients with normal weigh $\left(25^{\text {th }}-75^{\text {th }}\right)$ in those without joint involvement than in arthropathy group regarding to centile (charts of WHO). 
Table (1): Comparison between hemophilia with arthropathy group and hemophilia without arthropathy group regarding demographic data

\begin{tabular}{|c|c|c|c|c|c|c|}
\hline & & & $\begin{array}{c}\text { Hemophilia with } \\
\text { arthropathy group }\end{array}$ & $\begin{array}{l}\text { Hemophilia without } \\
\text { arthropathy group }\end{array}$ & t. test & P. value \\
\hline Age (years) & Mean & & $10.68 \pm 4.28$ & $7.17 \pm 4.12$ & 3.376 & 0.001 \\
\hline \multirow{4}{*}{ Sex } & \multirow{2}{*}{ Female } & No. & 0 & 1 & \multirow{4}{*}{$\begin{array}{c}\mathbf{X}^{2} \\
1.015\end{array}$} & \multirow[t]{4}{*}{0.314} \\
\hline & & $\%$ & $.0 \%$ & $3.0 \%$ & & \\
\hline & \multirow{2}{*}{ Male } & No. & 33 & 32 & & \\
\hline & & $\%$ & $100.0 \%$ & $97.0 \%$ & & \\
\hline
\end{tabular}

Table (2): Comparison between hemophilia with arthropathy group and hemophilia without arthropathy group regarding type of factor deficiency

\begin{tabular}{|c|c|c|c|c|c|c|}
\hline & & & $\begin{array}{c}\text { Hemophilia with } \\
\text { arthropathy } \\
\text { group }\end{array}$ & $\begin{array}{c}\text { Hemophilia } \\
\text { without } \\
\text { arthropathy } \\
\text { group } \\
\end{array}$ & $\mathbf{X}^{2}$ & P. value \\
\hline \multirow{4}{*}{$\begin{array}{l}\text { Type of factor } \\
\text { deficiency }\end{array}$} & \multirow{2}{*}{$\mathbf{A}$} & No. & 31 & 26 & \multirow[t]{4}{*}{3.216} & \multirow[t]{4}{*}{0.073} \\
\hline & & $\%$ & $93.9 \%$ & $78.8 \%$ & & \\
\hline & \multirow{2}{*}{ B } & No. & 2 & 7 & & \\
\hline & & $\%$ & $6.1 \%$ & $21.2 \%$ & & \\
\hline
\end{tabular}

Table (3): Comparison between hemophilia with arthropathy group and hemophilia without arthropathy group regarding degree of severity (factor level)

\begin{tabular}{|c|c|c|c|c|c|c|}
\hline & & & $\begin{array}{c}\text { Hemophilia with } \\
\text { arthropathy } \\
\text { group }\end{array}$ & $\begin{array}{c}\text { Hemophilia } \\
\text { without } \\
\text { arthropathy } \\
\text { group } \\
\end{array}$ & $\mathbf{X}^{2}$ & P. value \\
\hline \multirow{6}{*}{$\begin{array}{c}\text { Degree of } \\
\text { severity } \\
\text { (factor level) }\end{array}$} & \multirow{2}{*}{ mild } & No. & 0 & 5 & \multirow[t]{6}{*}{5.926} & \multirow[t]{6}{*}{0.04} \\
\hline & & $\%$ & $.0 \%$ & $15.2 \%$ & & \\
\hline & \multirow[t]{2}{*}{ Moderate } & No. & 17 & 17 & & \\
\hline & & $\%$ & $51.5 \%$ & $51.5 \%$ & & \\
\hline & \multirow[t]{2}{*}{ Severe } & No. & 16 & 11 & & \\
\hline & & $\%$ & $48.5 \%$ & $33.3 \%$ & & \\
\hline
\end{tabular}


Table (4): Comparison between hemophilia with arthropathy group and hemophilia without arthropathy group regarding site of bleeding otherthan big joints

\begin{tabular}{|c|c|c|c|c|c|c|}
\hline & & & $\begin{array}{c}\text { Hemophilia } \\
\text { with } \\
\text { arthropathy } \\
\text { group } \\
\end{array}$ & $\begin{array}{c}\text { Hemophilia } \\
\text { without } \\
\text { arthropathy } \\
\text { group } \\
\end{array}$ & $\mathbf{X}^{2}$ & $\begin{array}{c}P . \\
\text { value }\end{array}$ \\
\hline \multirow{34}{*}{$\begin{array}{l}\text { Site of } \\
\text { bleeding if } \\
\text { found }\end{array}$} & \multirow[t]{2}{*}{ big toe } & No. & 0 & 1 & \multirow{32}{*}{48.632} & \multirow{32}{*}{0.000} \\
\hline & & $\%$ & $.0 \%$ & $3.0 \%$ & & \\
\hline & \multirow[t]{2}{*}{ brusis in hand } & No. & 0 & 1 & & \\
\hline & & $\%$ & $.0 \%$ & $3.0 \%$ & & \\
\hline & \multirow{2}{*}{ gum } & No. & 0 & 6 & & \\
\hline & & $\%$ & $.0 \%$ & $18.2 \%$ & & \\
\hline & \multirow[t]{2}{*}{ gum and teeth } & No. & 0 & 4 & & \\
\hline & & $\%$ & $.0 \%$ & $12.1 \%$ & & \\
\hline & \multirow{2}{*}{$\begin{array}{c}\text { Hematoma in calf } \\
\text { muscle }\end{array}$} & No. & 0 & 1 & & \\
\hline & & $\%$ & $.0 \%$ & $3.0 \%$ & & \\
\hline & \multirow{2}{*}{$\begin{array}{l}\text { Hematoma in front of } \\
\text { head }\end{array}$} & No. & 0 & 2 & & \\
\hline & & $\%$ & $.0 \%$ & $6.1 \%$ & & \\
\hline & \multirow[t]{2}{*}{ Hematoma in leg } & No. & 0 & 1 & & \\
\hline & & $\%$ & $.0 \%$ & $3.0 \%$ & & \\
\hline & \multirow{2}{*}{$\begin{array}{c}\text { Hematoma in right } \\
\text { leg }\end{array}$} & No. & 0 & 1 & & \\
\hline & & $\%$ & $.0 \%$ & $3.0 \%$ & & \\
\hline & \multirow{2}{*}{$\begin{array}{c}\text { Hematoma in the } \\
\text { back }\end{array}$} & No. & 0 & 1 & & \\
\hline & & $\%$ & $.0 \%$ & $3.0 \%$ & & \\
\hline & \multirow[t]{2}{*}{ left eye and above it } & No. & 0 & 2 & & \\
\hline & & $\%$ & $.0 \%$ & $6.1 \%$ & & \\
\hline & \multirow[t]{2}{*}{ No } & No. & 33 & 5 & & \\
\hline & & $\%$ & $100.0 \%$ & $15.2 \%$ & & \\
\hline & \multirow{2}{*}{$\begin{array}{l}\text { stitching in } 2 \text { toes and } \\
\text { amputation of big teo }\end{array}$} & No. & 0 & 1 & & \\
\hline & & $\%$ & $.0 \%$ & $3.0 \%$ & & \\
\hline & \multirow[t]{2}{*}{ stitching in hand } & No. & 0 & 1 & & \\
\hline & & $\%$ & $.0 \%$ & $3.0 \%$ & & \\
\hline & \multirow[t]{2}{*}{ teeth } & No. & 0 & 3 & & \\
\hline & & $\%$ & $.0 \%$ & $9.1 \%$ & & \\
\hline & \multirow[t]{2}{*}{ wound in big fingers } & No. & 0 & 1 & & \\
\hline & & $\%$ & $.0 \%$ & $3.0 \%$ & & \\
\hline & \multirow[t]{2}{*}{ wound in left hand } & No. & 0 & 1 & & \\
\hline & & $\%$ & $.0 \%$ & $3.0 \%$ & & \\
\hline & \multirow[t]{2}{*}{ wound in right foot } & No. & 0 & 1 & & \\
\hline & & $\%$ & $.0 \%$ & $3.0 \%$ & & \\
\hline
\end{tabular}


Table (5): Comparison between hemophilia with arthropathy group and hemophilia without arthropathy group regarding weight $(\mathrm{kg})$ and weight percentile

\begin{tabular}{|c|c|c|c|c|c|c|}
\hline & & & $\begin{array}{l}\text { Hemophilia with } \\
\text { arthropathy } \\
\text { group }\end{array}$ & $\begin{array}{l}\text { Hemophilia } \\
\text { without } \\
\text { arthropathy } \\
\text { group } \\
\end{array}$ & $\mathbf{X}^{2}$ & P. value \\
\hline weight (kg) & Mean \pm SD & & $36.77 \pm 14.98$ & $24.56 \pm 11.15$ & t. test 3.757 & 0.000 \\
\hline \multirow{14}{*}{$\begin{array}{c}\text { weight } \\
\text { percentile }\end{array}$} & \multirow{2}{*}{$\begin{array}{c}\text { stunted }(<5 \text { th } \\
\text { percentile })\end{array}$} & No. & 1 & 1 & \multirow[t]{2}{*}{0.000} & \multirow[t]{2}{*}{1.000} \\
\hline & & $\%$ & $3.0 \%$ & $3.0 \%$ & & \\
\hline & \multirow{2}{*}{$\begin{array}{c}\text { severe } \\
\text { underweight }(5 \text { th }- \\
10 \text { percentile) }\end{array}$} & No. & 2 & 1 & \multirow[t]{2}{*}{0.349} & \multirow[t]{2}{*}{0.555} \\
\hline & & $\%$ & $6.1 \%$ & $3.0 \%$ & & \\
\hline & \multirow{2}{*}{$\begin{array}{l}\text { under weight }(10 \text { th } \\
-25 \text { percentile) }\end{array}$} & No. & 4 & 2 & \multirow[t]{2}{*}{0.733} & \multirow[t]{2}{*}{0.392} \\
\hline & & $\%$ & $12.1 \%$ & $6.1 \%$ & & \\
\hline & \multirow{2}{*}{$\begin{array}{c}\text { normal (25th }-75 \\
\text { percentile) }\end{array}$} & No. & 9 & 17 & \multirow[t]{2}{*}{4.062} & \multirow[t]{2}{*}{0.044} \\
\hline & & $\%$ & $27.3 \%$ & $51.5 \%$ & & \\
\hline & \multirow{2}{*}{$\begin{array}{l}\text { overweight (75th - } \\
90 \text { percentile) } \\
\end{array}$} & No. & 9 & 8 & \multirow[t]{2}{*}{0.079} & \multirow[t]{2}{*}{0.778} \\
\hline & & $\%$ & $27.3 \%$ & $24.2 \%$ & & \\
\hline & \multirow{2}{*}{$\begin{array}{c}\text { obese (90th }-95 \\
\text { percentile) }\end{array}$} & No. & 5 & 3 & \multirow[t]{2}{*}{0.569} & \multirow[t]{2}{*}{0.451} \\
\hline & & $\%$ & $15.2 \%$ & $9.1 \%$ & & \\
\hline & \multirow{2}{*}{$\begin{array}{c}\text { morbid obesity (> } \\
95 \text { percentile) }\end{array}$} & No. & 1 & 1 & \multirow[t]{2}{*}{0.000} & \multirow[t]{2}{*}{1.000} \\
\hline & & $\%$ & $3.0 \%$ & $3.0 \%$ & & \\
\hline
\end{tabular}

\section{DISCUSSION}

Regarding to demographic and clinical characteristics of patients, our study concluded that, there was significance difference in mean age of hemophilic arthropathy group and without arthropathy group. The mean age was $10.68 \pm 4.28$ and $7.17 \pm 4.12$, respectively with male predominance in both groups. These results are nearly in agreement with Chang et $\boldsymbol{a l}$. ${ }^{(7)}$ who reported that there is increase in age among hemophilic hropathyart. He reported that prevalence of hemophilic arthropathy represent $42.8 \%$ in PWH aged $4-10$ year, $64.3 \%$ in PWH aged 11-18 year. In addition, this prove that there is deterioration in joints with increasing age.

Moreover, male predominance in both groups and this match with Kulkarni and Soucie ${ }^{(8)}$ who said that hemophilia is most commonly seen in males as they only have one $\mathrm{X}$ - chromosome.

In our study, we found that there was no statistically significant difference between hemophilia with arthropathy and without arthropathy groups regarding type of factor deficiency. However, in both groups, hemophilia A (factor VIII deficiency) is more common (86\%) than hemophilia B factor deficiency (4\%) and this is in agreement with Singh and Vohra (9) who said that hemophilia $\mathrm{A}$ is more predominant than hemophilia B. Furthermore, this also agrees with ALFawaz et al. ${ }^{(10)}$ study from Poland and Windyga et al. (11) who reported that hemophilia A is predominant. In addition, Kar and Potins (12) reported that majority of patients are suffering from hemophilia A.

Our study showed that the most common joint affection was knee joint followed by elbow then ankle joint. As well as Karim et al. ${ }^{(13)}$ mentioned that the knee joint was predominant target joint in $90 \%$ of cases.

Our Study showed that the most common site of bleeding in hemophilic patients is gum (18.2\%) followed by gum and teeth (12.1\%).And this matches with Shastry et al. ${ }^{(14)}$ who said that hemophilia is characterized by bleeding from multiple sites, frequently manifested in mouth as gingival bleeding. In addition, Sonis and Musselman ${ }^{(15)}$ reported that an average $29.1 \%$ event per year in hemophilic patients, of which 9\% involved oral structures.

Our study showed that there was significant increase in number of hemophilic patients with normal weight $\left(25^{\text {th }}-75^{\text {th }}\right)$ in those without joint involvement than in arthropathy group. However, in hemophilia in general, we found that there was increase in weight (overweight/obesity) with hemophilia. This agrees with Hofstede et al. ${ }^{(16)}$ who found that prevalence of overweight increases in hemophilic children. In addition, these results match with CDC (17) who reported that the rate of overweight in children with hemophilia was $20 \%$ to $21 \%$ when compared to $11.5 \%$ to $13.7 \%$ in general pediatric population. Our study showed that obesity was $15.2 \%$ with arthropathy group and this prove that there is strong association between obesity and 
development of arthropathy. This is consistent with Christensen et al. ${ }^{(18)}$.

\section{CONCLUSION}

Our case control study showed male predominance and more prevalence of hemophilia A than B in both hemophilic groups (with or without hemoarthropathy). Weight showed statistically significant increase in hemophilia with arthropathy group than in hemophilia without arthropathy group. Regarding to H.A. our study reported that severity of H.A. correlate positively with weight.

\section{REFERENCES}

1. Acharya S, Kaplan R, Macdonald D et al. (2011): Neoangiogenesis contributes to the development of hemophilic synovitis. Blood, 117: 2484-2493.

2. Melchiorre D, Linari S, Matassi F et al. (2017): Pathogenesis of the haemophilic arthropathy. In: Frontiers in Arthritis, 1st ed.., Carulli, C., Ed.., Bentham Science Publishers: Sharjah, United Arab Emirates, Pp: 1-13.

3. Angelini D, Sood S (2015): Managing older patients with hemophilia. Hematology Am Soc Hematol Educ Program, 12: 41-47.

4. Srivastava A (2014): Haemophilia care: Beyond the treatment guideliens. Haemophilia, 20: 4-10.

5. Carr M, Tortella B (2015): Emerging and future therapies for hemophilia. J Blood Med., 6: 245-255.

6. World Health Organization (WHO) (2017): Obesity and overweight. www.who.int/mediacentre/factsheets/fs311/en.

7. Chang C, Li T, Cheng S et al. (2017): Prevalence and severity by age and other clinical correlates of haemophilic arthropathy of the elbow, knee and ankle among Taiwanese patients with haemophilia. Haemophilia, 23 (2): 284-291.
8. Kulkarni R, Soucie J (2011): Pediatric hemophilia: a review. Semin Thromb Hemost., 37 (7): 737-44.

9. Singh Y, Vohra K (2018): Epidemiological profile of patients with haemophilia at tertiary care center of Western Uttar Pradesh. International Journal of Contemporary Medicine Surgery and Radiology, 3 (4): 99-103.

10. Al Fawaz I, Gader A, Bahakim H et al. (1996): Hereditary bleeding disorder in Riyadh, Saudi Arabia. Konkle Ann Saudi Med., 16: 257-261.

11. Windyga J, Lopaciuk S, Stefanska E et al. (2004): Hemophilia and other inherited blood coagulation disorders in Poland. Pol Arch Med Wewn., 112 (4): 1197-202.

12. Kar A, Potnis M (2001): LELE Descriptive epidemiology 9 of hemophilia in Maharashtra India. Hemophilia, 7 (3): 561-567.

13. Karim M, Siddique R, Jamal C et al. (2013): Clinical profile of haemophilia in children in a tertiary care hospital. Bangladesh J Child Health, 37: 90-96.

14. Shastry S, Kaul R, Baroudi K et al. (2014): Dental considerations and management. $\mathbf{J}$ Int Soc Prev Community Dent., 4 (13): 147-52.

15. Sonis A, Musselman R (1982): Oral bleeding in classic hemophilia. Oral Surg Oral Med Oral Pathol., 53: 363-6.

16. Hofstede F, Fijnvandraat $\mathrm{K}$, Plug I et al. (2008): Obesity: a new disaster for haemophilic patients? A nationwide survey. Haemophilia, 14: 1035-1038.

17. CDC (2005): Report on the Universal Data Collection Program.

http://www.cdc.gov/ncbddd/hbd/documents/UDC7(1)

18. Christensen R, Henriksen M, Leeds A et al. (2015): Effect of weight maintenance on symptoms of knee osteoarthritis in obese patients: A twelve-month randomized controlled trial. Arthritis Care Res., 67: $640-650$. 